\title{
Evolution of Nanoscale Zero-valent Iron (nZVI) in Water: \\ Microscopic and Spectroscopic Evidence on the \\ Formation of Nano- and Micro-structured Iron Oxides
}

\author{
Airong Liu *, Jing Liu, Jinhao Han, Wei-xian Zhang* \\ State Key Laboratory for Pollution Control and Resource Reuse \\ College of Environmental Science and Engineering \\ Tongji University, Shanghai, China, 200092
}

Abstract

Knowledge on the transformation of nanoscale zero-valent iron $(\mathrm{nZVI})$ in water is essential to predict its surface chemistry including surface charge, colloidal stability and aggregation, reduction and sorption of organic contaminants, heavy metal ions and other pollutants in the environment. In this work, transmission electronic microscopy (TEM), X-ray diffraction (XRD) and Raman spectroscopy are applied to study the compositional and structural evolution of nZVI under oxic and anoxic conditions. Under anoxic conditions, the core-shell structure of $\mathrm{nZVI}$ is well maintained even after $72 \mathrm{~h}$, and the corrosion products usually contain a mixture of wustite $(\mathrm{FeO})$, goethite $(\alpha-\mathrm{FeOOH})$ and akaganeite $(\beta-\mathrm{FeOOH})$. Under oxic conditions, the core-shell structure quickly collapses to flakes or acicular-shaped structures with crystalline lepidocrocite $(\mathrm{\gamma}-\mathrm{FeOOH})$ as the primary end product. This work

\footnotetext{
*To whom correspondence should be addressed. Tel: +86-21-6598-2684; Fax:

+86-21-6598-3689 E-mail address: liuairong@tongji.edu.cn (Airong Liu)

*zhangwx@tongji.edu.cn (Wei-xian Zhang)
} 
provides detailed information and fills an important knowledge gap on the physicochemical characteristics and structural evolution of engineered nanomaterials in the environment.

Keywords: Nanoscale zero-valent iron; Evolution; Oxic water; Anoxic water

\section{Introduction}

Nanoscale zero-valent iron (nZVI) is an engineered nanomaterials widely used in environmental remediation and hazardous waste treatment [1-4]. nZVI has a classic core-shell structure, which consists of a metallic iron core encapsulated by a thin iron oxide shell of a few nanometers [5]. This core-shell nanomaterial with two nano-constituents has multifaceted functions for contaminant separation and transformation. The metallic iron core serves as an electron source and exerts a reducing character, whereas the oxide shell promotes the adsorption of contaminants via electrostatic interactions and surface complexation [6].

In wastewater treatment and groundwater remediation, nZVI can partially or completely transform from metal iron $\left(\mathrm{Fe}^{0}\right)$ to nontoxic iron oxide/hydroxides commonly found in sediments and soils, resulting in significant variations in the nanoparticle structure and composition. The iron oxidation or corrosion also varies depending on the type of irons, contaminants, solution composition and environmental conditions [11-20]. For example, an nZVI (e.g., RNIP from Toda Kogyo Corp.) produced by the hydrogen reduction of ferric oxides [13], the iron oxide shell generated by the gradual exposure to the atmosphere could inhibit 
further oxidation of the nZVI particles [14]. The shell-modified RNIP particles formed new iron minerals, goethite, $\mathrm{Fe}(0)$ and magnetite when put into water [15]. Research on the chemical transformation of $\mathrm{nZVI}$ in groundwater treatment suggested that the differences in groundwater chemistry such as $\mathrm{pH}$, carbonate and phosphate can affect the corrosion products [16-20]. For example, in our previous study, the aging effect of nZVI nanoparticles synthesized by borohydride reduction of $\mathrm{FeCl}_{3}$, was investigated over a period of 90 days in static water [21]. Similarly, nZVI was oxidized primarily to the iron oxide-hydroxide lepidocrocite under flowing aerated water [22]. Results showed that the structure, shape and composition of nZVI changed with time after exposed to water. New applications of nZVI for industrial wastewater treatment provide new challenges on the study of its aging effects $[23,24]$. In the reactors for industrial water treatment, the nZVI suspension is typically agitated intensely to achieve uniform dispersion in water. The corrosion products under this condition not only affect its removal capacity, but also the final state and fate of iron materials after their emplacement. Until now, comprehensive study of corrosion products for nZVI under oxic and anoxic water is limited, and is clearly needed to enhance our understanding on the longevity, reactivity, fate, transport and potential toxicity of $n Z V I$.

Objectives of this study are to investigate the chemical transformation, morphological and structural evolution of nZVI under both oxic and anoxic conditions. Fresh- and aged- nZVIs are characterized with transmission electron microscopy (TEM), X-ray diffraction (XRD) and Raman spectroscopy. 
Results obtained can contribute to the expanded understanding of nZVI geochemical recycling, oxidation mechanisms, kinetics, and more importantly, the final products and fate of $\mathrm{nZVI}$ in the environment.

\section{Experimental}

\subsection{Materials and chemicals}

All chemicals used in the study, for example, $\mathrm{FeCl}_{3} \cdot 6 \mathrm{H}_{2} \mathrm{O}(\geq 99 \%)$ and $\mathrm{NaBH}_{4}(\geq 98 \%)$, were analytical grade or better, and all were obtained from Sigma-Aldrich. Chemical stock solutions were prepared using deionized water. Ultrahigh-purity $\mathrm{N}_{2}(\geq 99.999 \%)$ was used to strip dissolved oxygen in water.

\subsection{Preparation of fresh and aged $n Z V I$}

Procedures used in the preparation of iron nanoparticles have been published previously $[5,6]$. In brief, it entailed slowly adding a 1:1 volume ratio of $0.25 \mathrm{M}$ sodium borohydride into $0.045 \mathrm{M}$ ferric chloride solution. The jet-black nanoparticles were collected by vacuum filtration and refrigerated in a sealed polyethylene container in $95 \%$ ethanol until use. The residual water content of the nanoparticles as used typically varied between 40 and $50 \%$. Average size of the synthesized nZVI was $60 \mathrm{~nm}[6]$. The $\mathrm{nZVI}$ produced had surface areas in the range of $20-40 \mathrm{~m}^{2} / \mathrm{g}$. Iso-electric point (IEP) of $\mathrm{nZVI}$ in water was found to be near $\mathrm{pH}$ of 8.3 [25].

Corrosion products of $\mathrm{nZVI}$ under oxic water were produced by charging fresh nZVI $(0.5 \mathrm{~g})$ into deionized water $(100 \mathrm{~mL})$, vigorously stirred with an agitator at $300 \mathrm{rpm}$ under ambient conditions. At certain time intervals, the reacted nZVIs were separated, and then stored in ethanol until use.

Corrosion products of $\mathrm{nZVI}$ under anoxic water were prepared by putting 
fresh nZVI $(0.5 \mathrm{~g})$ into sealed serum bottles containing $100 \mathrm{~mL}$ of deionized water (previously degassed using $\mathrm{N}_{2}$ ). The aging time was $2 \mathrm{~h}, 6 \mathrm{~h}, 12 \mathrm{~h}, 24 \mathrm{~h}$, and $72 \mathrm{~h}$ at room temperature $\left( \pm 0.5^{\circ} \mathrm{C}\right)$. The products were then separated and stored in ethanol until use.

\subsection{Solid-phase characterization of fresh nZVI and aged nZVI}

High-resolution TEM analyses were performed using a TEM 2100 FXII (JEOL, Japan) operated at $200 \mathrm{kV}$ and with selected area electron diffraction (SAED). Specimens were prepared for TEM analysis by allowing a drop of nZVI suspension in ethanol to evaporate onto a carbon film. The samples were then put into a vacuumed box until the ethanol was evaporated.

XRD analyses were conducted using a D8 Advance X (Bruker, Germany), operated at $40 \mathrm{KV}$ and $40 \mathrm{~mA}$ with $\mathrm{Cu} \mathrm{Ka}$. Samples were prepared by pressing the $\mathrm{nZVI}$ particles onto the glass plates for $\mathrm{XRD}$ analysis. Continuous scans from 10 to $80^{\circ}$ at $2 \theta$ were collected with a step size of $0.01^{\circ}$ and a count time of $0.2 \mathrm{~s}$ per step.

Raman spectra were obtained using a LabRam-1B (Jobin Yvon, France) with a $632 \mathrm{~nm} \mathrm{He-Ne} \mathrm{laser.} \mathrm{The} \mathrm{samples} \mathrm{were} \mathrm{put} \mathrm{onto} \mathrm{glass} \mathrm{plates} \mathrm{for} \mathrm{Raman}$ analysis. Approximately $1 \mathrm{~mW}$ of laser irradiation was used to excite the samples. Spectra were collected over the range $4000-100 \mathrm{~cm}^{-1}$ and averaged over 10 scans, each with an exposure time of $10 \mathrm{~s}$.

\section{$2.4 \mathrm{pH}$ and $E_{h}$ measurements}

$100 \mathrm{~mL}$ of distilled water was added to a four-neck flask fitted with a 
customized rubber stopper containing ports for $\mathrm{pH}$ and oxidation-reduction potential (ORP) electrodes and sampling. A variable speed mixer set at 300 rpm helped to ensure well-mixed conditions. Measured dissolved oxygen levels were generally less than $0.1 \mathrm{mg} \cdot \mathrm{L}^{-1}$ after 30 min of $\mathrm{N}_{2}$ purging. Then the $\mathrm{nZVI}$ was put into the flask to form the suspension with the concentration of $100 \mathrm{mg} \cdot \mathrm{L}^{-1}$. A pH (PHSJ-4F) and ORP meter (ORP501, Shanghai REX Instrument Factory) were put into the suspension to monitor the $\mathrm{pH}$ and standard potential. Measured redox potential readings $(\mathrm{mV})$ were converted to $E_{h}$, the potential relative to the standard hydrogen electrode, as a function of solution temperature by adding $+202 \mathrm{mV}$ at $25{ }^{\circ} \mathrm{C}$ to the ORP values.

\section{Results and Discussion}

\subsection{TEM imaging analysis}

Fig. 1 presents high-resolution TEM images that illustrate the changes of particle morphology of $\mathrm{nZVI}$ under oxic and anoxic conditions. As shown in Fig.1a, fresh $\mathrm{nZVI}$ particles synthesized by the borohydride reduction method aggregate to form chain-like structures with length on the order of a few micrometers due to magnetic and electrostatic interactions. The core-shell structure of the single particle can be observed clearly (Figs. 1b and 1c), that is, a metallic iron core surrounded with a thin iron oxide shell (2 4 $\mathrm{nm})$. As shown in Fig. 1c, when $\mathrm{nZVI}$ is placed in anoxic water for $72 \mathrm{~h}$, the core-shell structure is well maintained similar with that of fresh nZVI. Under anoxic condition, the rate of oxidation for $n Z V I$ is slow. These findings support that $n Z V I$ likely has a long life-time in the subsurface environment.

The $\mathrm{nZVI}$ particles are still spherical with the majority in the size range of 
50-100 nm after reactions for $2 \mathrm{~h}$ under oxic condition (Fig. 1d). With the progress of aging time from 6 to $24 \mathrm{~h}$ (Fig. 1e-g), the fraction of the core-shell structures decreases while amorphous spheres are observed. When the $\mathrm{nZVI}$ particles were put into the static water for a certain number of days, a complete loss of the $\mathrm{Fe}(0)$ core and the appearance of hollowed-out oxide shells were observed [22]. The small dot-like structures in Fig. 1e-i illustrate the possible dissolution-precipitation mechanism responsible for the corrosion product formation. Iron oxides in the amorphous spheres can first dissolve to $\mathrm{Fe}(\mathrm{II}) / \mathrm{Fe}(\mathrm{III})$, and then reprecipitate into an iron hydroxide phase. This in turn evolves to the apparent crystallite phase over a longer time period. The amorphous iron oxides are energetically unstable and eventually replaced by a thermodynamically more stable crystallite phase according to the Gay-Lussac-Oswald ripening rule on oxidation and corrosion of metallic iron to Fe(III) oxide/hydroxide [26].

Some flaky substances can be observed in Fig. 1f and the quantities increase with the progress of the aging time. Although some particles are still circular even for the nZVI aged for 24h (Fig. 1g), the core-shell structure almost disappears (Fig. 1h). According to the XRD patterns as in Fig. 2, the circular spheres for 24-h particles are composed of iron oxides, magenetite/maghemite. The sizes of flaky-shaped substances dominated with the several micrometers, become much larger with the progress of aging time. Fig. $1 \mathrm{~h}$ and $1 \mathrm{i}$ depict the images of $\mathrm{nZVI}$ particles aged in oxic water for $48 \mathrm{~h}$ and $72 \mathrm{~h}$, respectively, with lepidocrocite accounting for the presence of flaky structures $[10,27]$. The SAED patterns of the corrosion products after 72-h-aging indicate that the flaky structures are single-crystal phase. 

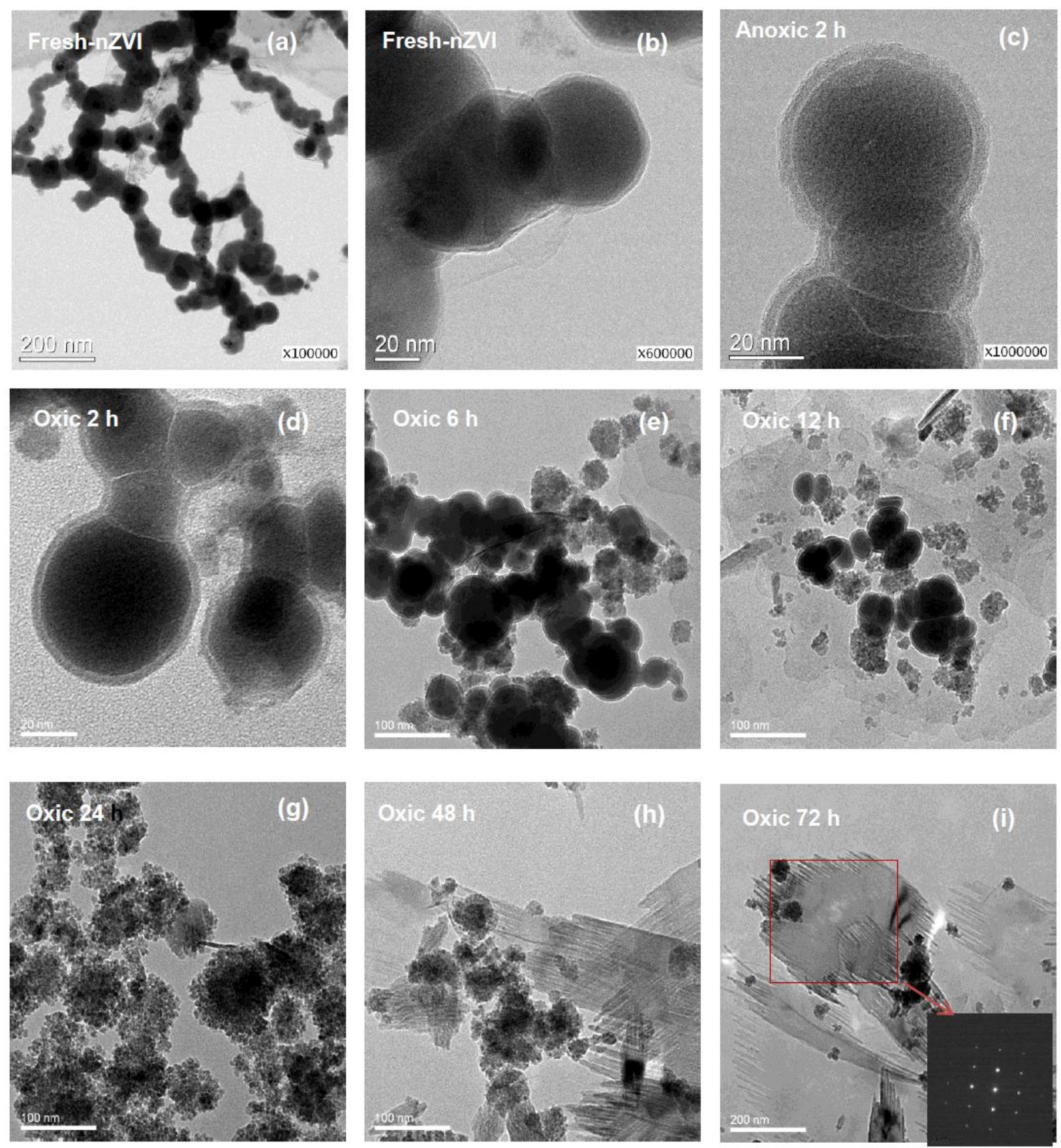

Fig. 1. TEM images of $(a, b)$ fresh- $n Z V I,(c) n Z V I$ eroded in anoxic water for $72 \mathrm{~h}$, and (d-i) nZVI oxidized in oxic water over different time periods. 


\subsection{XRD analysis}

Fig. 2 shows the XRD data of corrosion products of $\mathrm{nZVI}$ under oxic and anoxic water over a period of $72 \mathrm{~h}$. Fig.2a contains the XRD patterns of freshand oxidized nZVI in oxic water. The broad peak of fresh nZVI at $2 \theta$ of $44^{\circ}-45^{\circ}$ proves the small particle size and size distributions of $\alpha-\mathrm{Fe}^{0}$ with indexes of (110) (JCPDS No. 06-0696) [6]. Meanwhile, the aged nZVI particles possess clear iron oxide/hydroxide peaks in the XRD patterns, which become more distinct and stronger with the progress of aging time. When put into water, some metal iron nanoparticles are oxidized into iron oxide/hydroxides. In the aqueous solution, $\mathrm{Fe}^{2+}$ is first formed on the surface, which reacts with $\mathrm{H}_{2} \mathrm{O} / \mathrm{O}_{2}$ to form hydroxide or oxyhydoxide [28,29]. Representative reaction mechanisms may include:

$$
\begin{gathered}
\mathrm{Fe}^{0}+2 \mathrm{H}_{2} \mathrm{O} \rightarrow \mathrm{Fe}^{2+}+\mathrm{H}_{2}+2 \mathrm{OH}^{-} \\
\mathrm{Fe}^{0}+\mathrm{O}_{2}+2 \mathrm{H}_{2} \mathrm{O} \rightarrow 2 \mathrm{Fe}^{2+}+4 \mathrm{OH}^{-} \\
6 \mathrm{Fe}^{2+}+\mathrm{O}_{2}+6 \mathrm{H}_{2} \mathrm{O} \rightarrow 2 \mathrm{Fe}_{3} \mathrm{O}_{4}(\mathrm{~s})+12 \mathrm{H}^{+} \\
\mathrm{Fe}^{2+}+2 \mathrm{OH}^{-} \rightarrow \mathrm{Fe}(\mathrm{OH})_{2}(\mathrm{~s}) \\
6 \mathrm{Fe}(\mathrm{OH})_{2}(\mathrm{~S})+2 \mathrm{O}_{2} \rightarrow 2 \mathrm{Fe}_{3} \mathrm{O}_{4}+6 \mathrm{H}_{2} \mathrm{O}
\end{gathered}
$$

As seen in the XRD patterns, the intensity of the $\mathrm{Fe}^{0}$ peaks gradually subsides. When the aging time is up to $24 \mathrm{~h}$, the $\mathrm{Fe}^{0}$ peaks start to disappear and peaks of magnetite $\left(\mathrm{Fe}_{3} \mathrm{O}_{4}\right)$, maghemite $\left(\gamma-\mathrm{Fe}_{2} \mathrm{O}_{3}\right)$ and lepidocrocite $(\gamma-\mathrm{FeOOH})$ start to emerge (Fig. 2a).

It should be noted that the XRD patterns of $\mathrm{Fe}_{3} \mathrm{O}_{4}$ and $\gamma-\mathrm{Fe}_{2} \mathrm{O}_{3}$ in the nanoparticles cannot be clearly distinguished. It was reported that $\mathrm{Fe}_{3} \mathrm{O}_{4}$ can transform to $\gamma-\mathrm{Fe}_{2} \mathrm{O}_{3}[30]$. $\mathrm{Fe}_{3} \mathrm{O}_{4}$ exists in an inverse spinel structure where the 
$\mathrm{Fe}^{2+}$ is in an octahedral oxygen environment along with half of the $\mathrm{Fe}^{3+}$. The other half of the $\mathrm{Fe}^{3+}$ exists in a tetrahedral oxygen environment. Oxidation of $\mathrm{Fe}^{2+}$ to $\mathrm{Fe}^{3+}$, without a change in crystal structure, leads to $\gamma-\mathrm{Fe}_{2} \mathrm{O}_{3}[30]$. In the presence of oxygen or other aqueous oxidants $(\mathrm{Cr}(\mathrm{VI}), \mathrm{Ag}(\mathrm{I})$, carbon tetrachloride), $\mathrm{Fe}_{3} \mathrm{O}_{4}$ magnetite may undergo topotactic oxidation to produce maghemite, as illustrated by the following reaction:

$$
3 \mathrm{Fe}_{3} \mathrm{O}_{4}+\frac{1}{2} \mathrm{O}_{2}+2 \mathrm{H}^{+} \rightarrow 4 \gamma-\mathrm{Fe}_{2} \mathrm{O}_{3}+\mathrm{Fe}^{2+}+\mathrm{H}_{2} \mathrm{O}
$$

$\mathrm{Fe}_{3} \mathrm{O}_{4} / \gamma-\mathrm{Fe}_{2} \mathrm{O}_{3}$ and $\gamma-\mathrm{FeOOH}$ are detected in the particles aged for 48 to $72 \mathrm{~h}$ in the oxic water. However, the relative intensity of various mineral phases is different. $\gamma-\mathrm{FeOOH}$ is the predominant mineral until $48 \mathrm{~h}$. The presence of $\gamma-\mathrm{FeOOH}$ as an oxidized product has been favored by the continuous supply of dissolved oxygen [Eqn. (7-9)] [31]:

$$
\begin{gathered}
4 \mathrm{Fe}^{0}+3 \mathrm{O}_{2}+2 \mathrm{H}_{2} \mathrm{O} \rightarrow 4 \gamma-\mathrm{FeOOH} \\
4 \mathrm{Fe}_{3} \mathrm{O}_{4}+\mathrm{O}_{2}+6 \mathrm{H}_{2} \mathrm{O} \rightarrow 12 \gamma-\mathrm{FeOOH} \\
\gamma-\mathrm{Fe}_{2} \mathrm{O}_{3}+\mathrm{H}_{2} \mathrm{O} \rightarrow 2 \gamma-\mathrm{FeOOH}
\end{gathered}
$$

These results suggest that the corrosion of $\mathrm{nZVI}$ in oxygenated water clearly favors the formation of iron oxyhydroxide $(\mathrm{FeOOH})$ over iron oxides. For $\mathrm{nZVI}$ aged over long periods of time, the eventual product in oxic water is mostly $\gamma$-FeOOH [27]. 

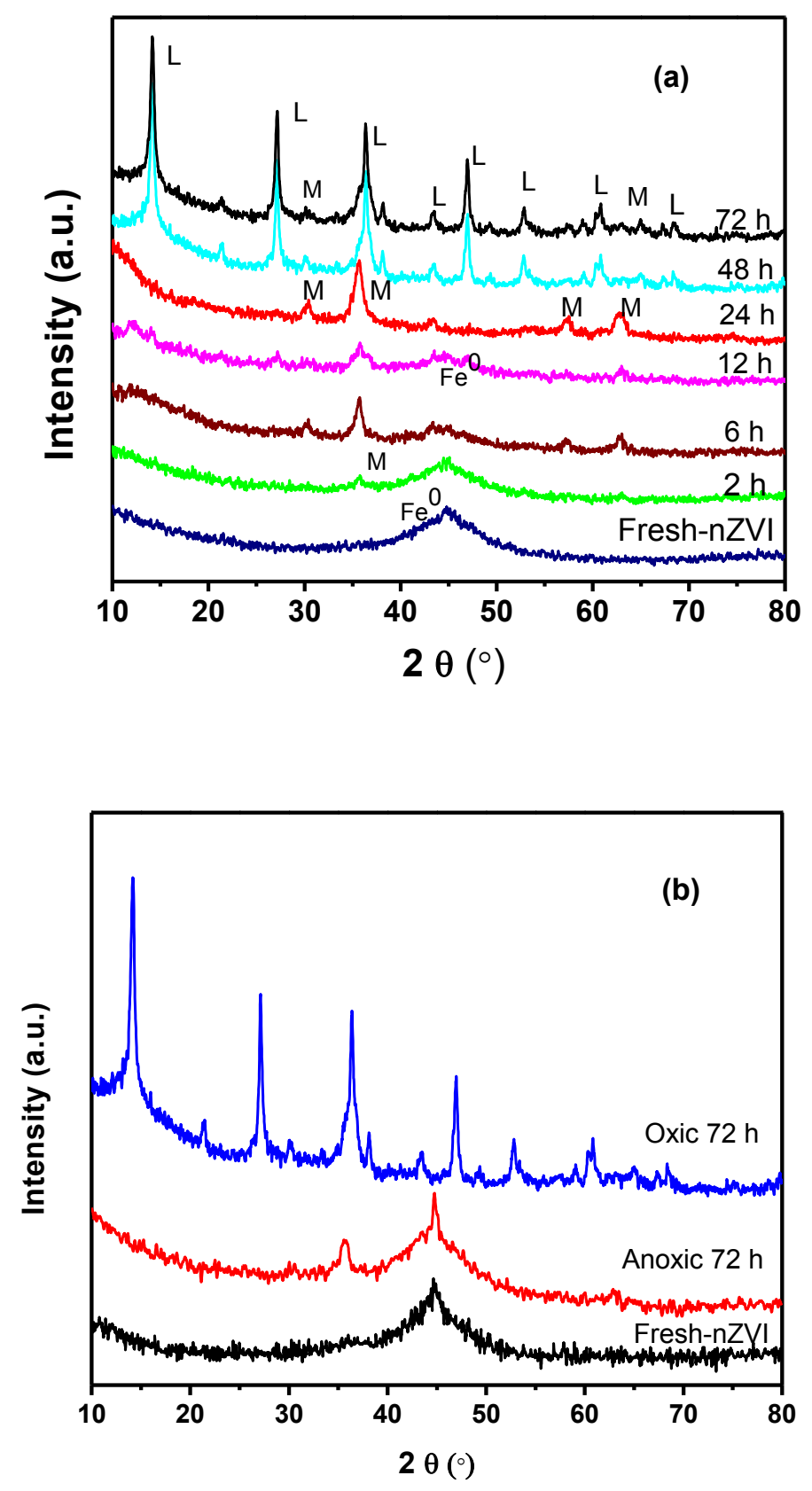

Fig. 2. (a) XRD analysis of fresh $n Z V I$ and oxidized $n Z V I$ as function of time in oxic water. Peaks are referred to magnetite/maghemite $\left(\mathrm{Fe}_{3} \mathrm{O}_{4} / \gamma-\mathrm{Fe}_{2} \mathrm{O}_{3}\right)(\mathrm{M})$, lepidocrocite $(\gamma-\mathrm{FeOOH})(\mathrm{L})$, and $\mathrm{nZVI}$ $\left(\mathrm{Fe}^{0}\right)$. (b) XRD analysis of fresh-nZVI, and $\mathrm{nZVI}$ under both anoxic and oxic water for $72 \mathrm{~h}$. 
Fig. $2 \mathrm{~b}$ shows the XRD patterns of fresh- and 72-h-aged $\mathrm{nZVI}$ under anoxic and oxic conditions. In contrast to the sharp peaks of 72-h-aged nZVI under oxic condition, there is little difference between the 72-h-aged nZVI in anoxic water and fresh-nZVI. Results prove that the reaction rate between $\mathrm{nZVI}$ and water under the anoxic condition is slow. Relative small peaks of $\mathrm{Fe}_{3} \mathrm{O}_{4}$ are observed in Fig. $2 \mathrm{~b}$, which is consistent with previous report on the corrosion products in the anoxic environment [31]. However, the corrosion products vary and depend on the conditions under which the iron oxides were formed. The following Raman data can provide evidence on the formation of new products under anoxic conditions

\subsection{Raman analysis}

Raman spectroscopy is especially useful for characterizing poorly defined minerals or minerals not easily distinguished by conventional methods (e.g., XRD). The method has been widely used for the analysis of iron oxidation and scaling in steel corrosion processes [32].

The Raman spectra of fresh and corrosion products aged in oxic water are shown in Fig. 3a. Four clear bands at 217, 280, 388 and $595 \mathrm{~cm}^{-1}$ are observed in the Raman spectrum of nZVI particles aged less than $12 \mathrm{~h}$. The combination of bands, at $220,290,300$, and $412 \mathrm{~cm}^{-1}$ is best used for the identification of hematite. In this study the iron oxides, magnetite/maghemite $\left(\mathrm{Fe}_{3} \mathrm{O}_{4} / \gamma-\mathrm{Fe}_{2} \mathrm{O}_{3}\right)$ are the mainly components within the shell of $\mathrm{nZVI}$ by the XRD data. The hematite detected by Raman spectra are ascribed to the transformation of the iron (oxy) hydroxides irradiated by laser, which demonstrates the absence of hematite in the XRD spectra. The band at 595 
$\mathrm{cm}^{-1}$ appears in Raman spectra of $\mathrm{nZVI}$ aged for $12 \mathrm{~h}$, which is the characteristic Raman peak of wustite. The peak of wustite is not found in XRD because the sensitivity of the XRD instrument may have been insufficient to detect small amounts of wustite [33]. Moreover, wustite is unstable. The presence of $\mathrm{Fe}(\mathrm{II})$ oxide provides the evidence that $\mathrm{Fe}(\mathrm{II})$ formation is an intermediate step in the nZVI evolution.

When the aging time increases up to $24 \mathrm{~h}$, the new broad band from 660 to $710 \mathrm{~cm}^{-1}$ indicates co- existence of maghemite $\left(\gamma-\mathrm{Fe}_{2} \mathrm{O}_{3}, 665,730 \mathrm{~cm}^{-1}\right)$, magnetite $\left(\mathrm{Fe}_{3} \mathrm{O}_{4}, 670 \mathrm{~cm}^{-1}\right)$. The results are consistent with XRD results, which also demonstrate that $\mathrm{Fe}_{3} \mathrm{O}_{4}$ and $\gamma-\mathrm{Fe}_{2} \mathrm{O}_{3}$ are the major components for iron oxide shell in 1- to 24-h-aged products. When the nZVI aging time is prolonged to $48 \mathrm{~h}$, or even up to $72 \mathrm{~h}$, the peak positions at $250,377,526$, and $650 \mathrm{~cm}^{-1}$ are in good agreement with the Raman spectra of lepidocrocite [34]. The typical Raman bands of the different iron oxide and (oxy)hydroxide phases are listed in Table 1. 

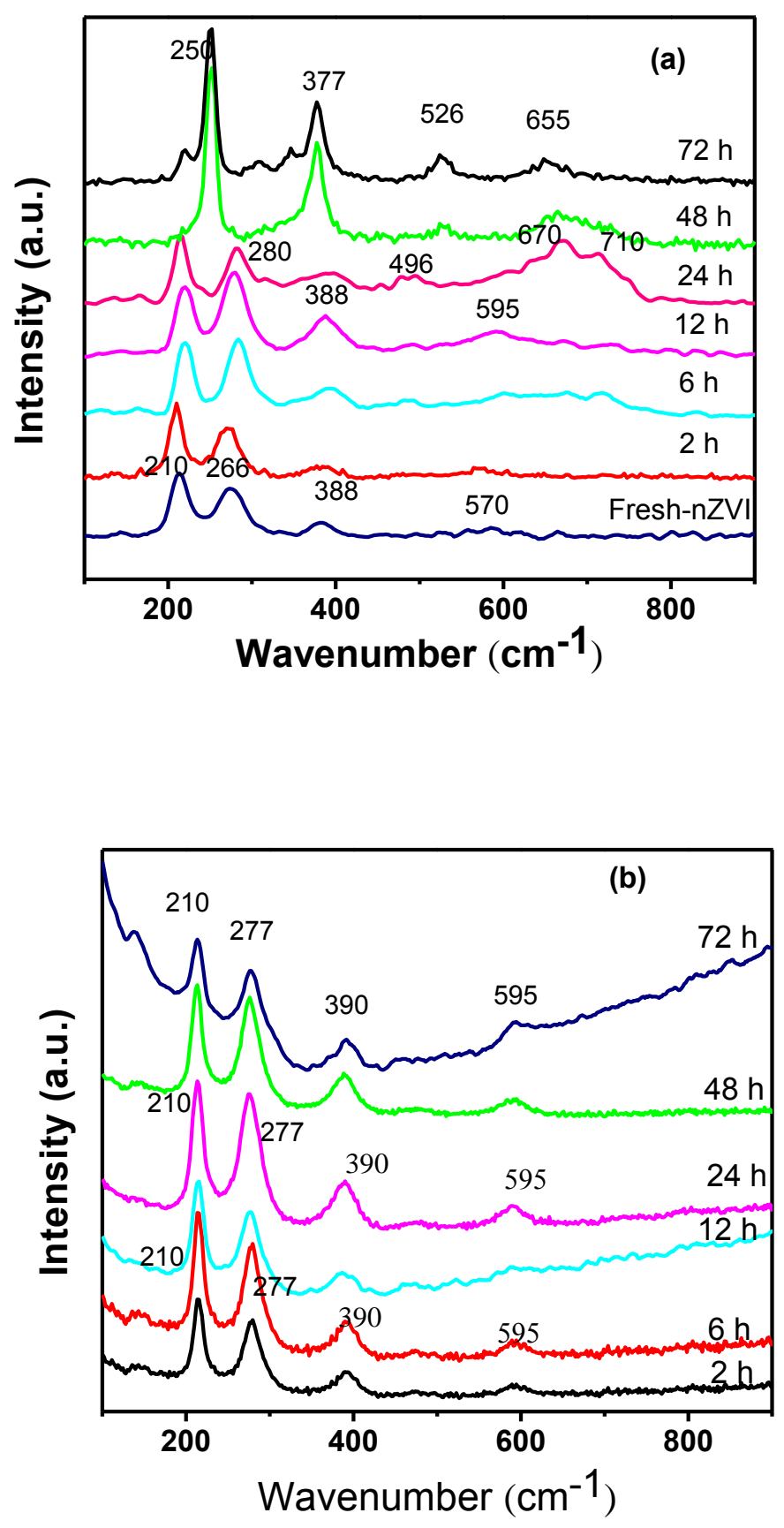

Fig. 3. Raman spectra of $n Z V I$ as a function of time under (a) oxic and (b) anoxic conditions ([nZVI] $\left.=5 \mathrm{~g} \cdot \mathrm{L}^{-1}\right)$ 
Fig. $3 b$ shows the Raman spectra of $n Z V I$ aging in anoxic water from 2 to $72 \mathrm{~h}$. Four bands are observed at 210, 280, 388 and $595 \mathrm{~cm}^{-1}$. The clear band at about $390 \mathrm{~cm}^{-1}$ provides evidence on the existence of goethite/akaganeite in corrosion products. The peak at $595 \mathrm{~cm}^{-1}$, which is the characteristic of $\mathrm{FeO}$, is apparent under the anoxic condition while the anoxic condition favors the formation of $\mathrm{FeO}, \alpha-\mathrm{FeOOH}$ and $\beta-\mathrm{FeOOH}$.

Table 1. Raman shifts for iron oxides and (oxy) hydroxides

\begin{tabular}{|c|c|}
\hline Iron oxides \& (oxy)hydroxides & Raman shift $\left(\mathrm{cm}^{-1}\right)$ \\
\hline Hematite $\left(\alpha-\mathrm{Fe}_{2} \mathrm{O}_{3}\right)$ & $\underline{\mathbf{2 1 0}}, 276,382,1300$ \\
\hline Lepidocrocite $(\gamma$-FeOOH) & $\underline{\mathbf{2 5 0}}, \underline{379}, 526,650$ \\
\hline Goethite $(\alpha-\mathrm{FeOOH})$ & $244299 \underline{385} 480548681$ \\
\hline Akaganeite $(\beta-\mathrm{FeOOH})$ & $\underline{311}, \underline{390}, \underline{415}, 537,614,717$ \\
\hline Wuestite ( $\mathrm{FeO})$ & $\underline{595}$ \\
\hline Magnetite $\left(\mathrm{Fe}_{3} \mathrm{O}_{4}\right)$ & $310540 \underline{670}$ \\
\hline Maghematite $\left(\gamma-\mathrm{Fe}_{2} \mathrm{O}_{3}\right)$ & $350,512, \underline{670} \underline{720}$ \\
\hline
\end{tabular}

Underlined and bold figures represent very strong while underlined figures represent strong. These results are typical for iron oxide [33, 34].

\section{4 $E_{h}$ and $p H$ of the solution}

Zero-valent iron $(\mathrm{ZVI})$ is a reactive metal with a standard electrode potential, $\mathrm{E}_{\mathrm{h}}{ }^{0}$, of $-0.44 \mathrm{~V}$. Standard potential (often measured as ORP) has been widely used to assess the performance of $n Z V I$ [35]. The value of the ORP is sensitive to a number of fundamentally significant processes. Positive 
values of ORP generally imply oxidizing conditions while negative ORP usually indicates reducing conditions in water. Under anoxic conditions typical of the subsurface environment, $\mathrm{Fe}(0)$ in $\mathrm{nZVI}$ quickly eliminates residual dissolved oxygen and reacts slowly with water. The zero-valent iron-mediated redox reactions produce a characteristic increase in solution $\mathrm{pH}$ and a concomitant decline in solution potential $\left(E_{h}\right)[25]$.

In our experiments, a combination $\mathrm{Ag} / \mathrm{AgCl}$ reference electrode is used in the monitoring of redox potential, and then the standard $E_{h}$ is obtained by adding $+202 \mathrm{mV}$ to the measured redox potential readings [25]. According to Fig. $4 a$, the $E_{h}$ value of the solution declines quickly (presumably due to a combination of rapid electrode polarization and solution equilibration effects) [35] after $\mathrm{nZVI}$ is placed into water, then approaches to a minimum value $\left(E_{h, \min }\right)$, usually within 20 min and remains stable after that. The $E_{h, \text { min }}$ values change with the aging time. When oxidized $\mathrm{nZVI}$ (less than $6 \mathrm{~h}$ ) is put into water, $E_{h, m i n}$ of the solution is mostly in the range of -400 to $-500 \mathrm{mV}$, close to that of fresh-nZVI. However, the addition of nZVI nanoparticles aged more than $24 \mathrm{~h}$ into water, produces $\mathrm{E}_{\mathrm{h} \text {,min }}$ only slightly lower than the initial value (50-200 $\mathrm{mV}$ ). Results indicate that the $\mathrm{nZVI}$ nanoparticles are extensively oxidized to iron oxides after more than $24 \mathrm{~h}$ contacting with oxic water, which are consistent with the TEM pictures as well as XRD data. In oxic water after $24 \mathrm{~h}$, $\mathrm{nZVI}$ is first transformed to the iron oxide spheres, then to flakey-shaped oxyhydroxides. The slight decrease of $E_{h, \min }$ for $n Z V I$ aging from 24 to 72 maybe ascribe to the formation of different mineral phases of iron oxides in the oxic water. 

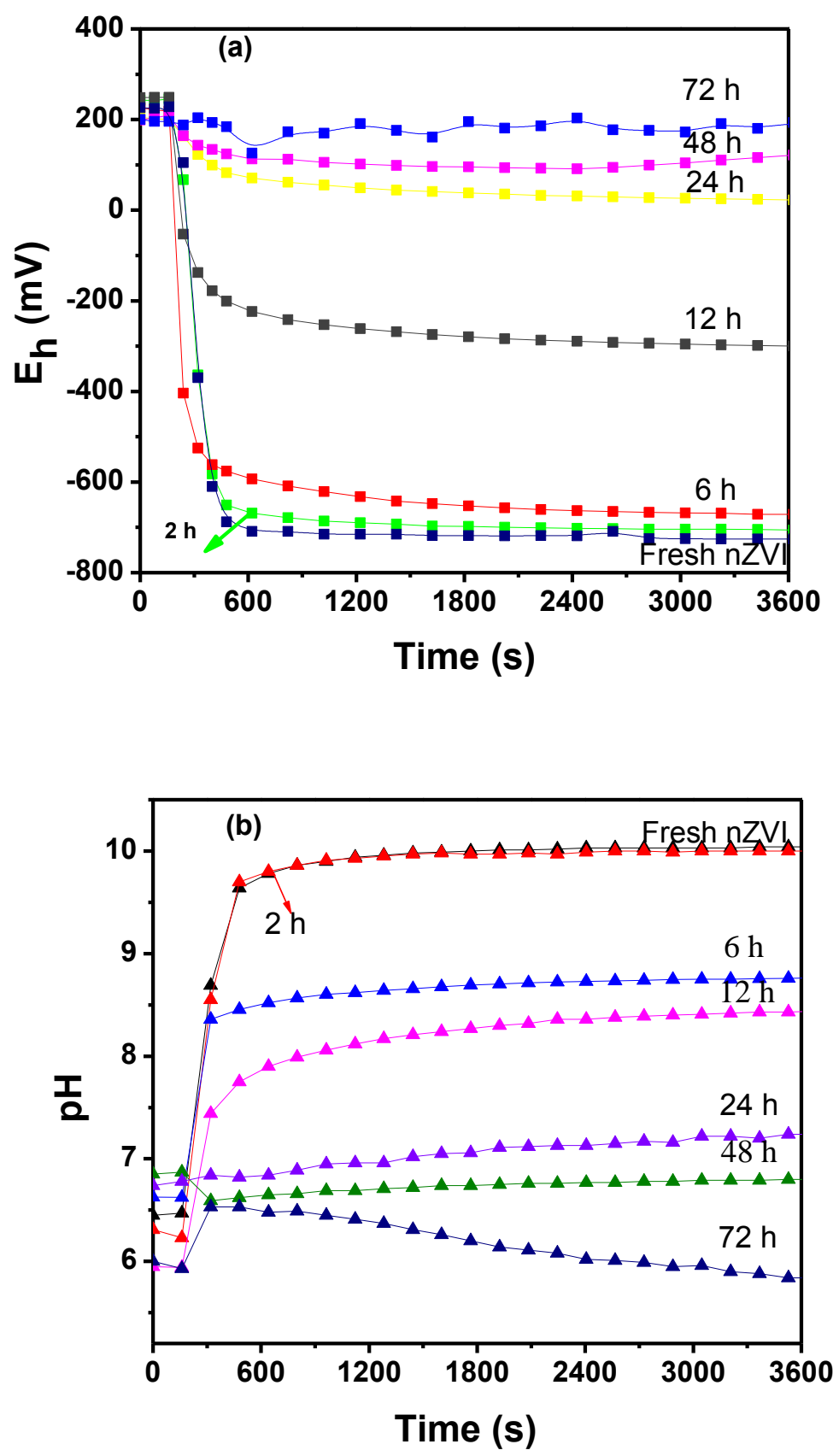

Fig. 4. $E_{h}$ and $p H$ of fresh- and $n Z V I$ particles under oxic water as function of time. 
Our experiments show a typical increase in $\mathrm{pH}$ from $\sim 6$ to the range of 8-10 when $\mathrm{nZVI}$ (aging time $<12 \mathrm{~h}$ ) is put into solution. The addition of iron nanoparticles can generate hydrogen gas, produce divalent iron and lead to ascending solution $\mathrm{pH}$. For the $24-\mathrm{h}$-aging $\mathrm{nZVI}, \mathrm{pH}$ value of the solution is relatively stable at $\mathrm{pH}$ 7. Results show that the metallic iron in $\mathrm{nZVI}$ is fully consumed at this stage. The minor changes of solution $\mathrm{pH}$ for $\mathrm{nZVI}$ after 48 and $72 \mathrm{~h}$ aging maybe ascribe to the dissolution of iron oxides.

\subsection{Reaction mechanisms}

A conceptual model on the transformation of $\mathrm{nZVI}$ in water is illustrated in Fig. 5, which highlights the experimental results obtained in the study. The formed mineral phases on the particle surface and the core-shell structure of $\mathrm{nZVI}$ vary with the aging progress and environmental conditions. Fresh $\mathrm{nZVI}$ has a core-shell structure with spherical shape. The core-shell structure can be maintained over an extended period of time (e.g., $72 \mathrm{~h}$ ) under anoxic condition. The oxidation products of $\mathrm{nZVI}$ in anoxic water for $72 \mathrm{~h}$ are the mixture of $\mathrm{FeO}$, $\alpha-\mathrm{FeOOH}$ and/or $\beta-\mathrm{FeOOH}$. Under oxic conditions, the core-shell structure transforms into the circular spheres composed of magenetite/maghemite when aging time is up to $24 \mathrm{~h}$. After $48 \mathrm{~h}$ aging in water, the spheres of iron oxides evolve into new flaky and/or acicular-shaped phases. With continuously supply of oxygen for $\mathrm{nZVI}$ in water, the products are mainly of flaky-shaped lepidocrocite, $\gamma$-FeOOH. 


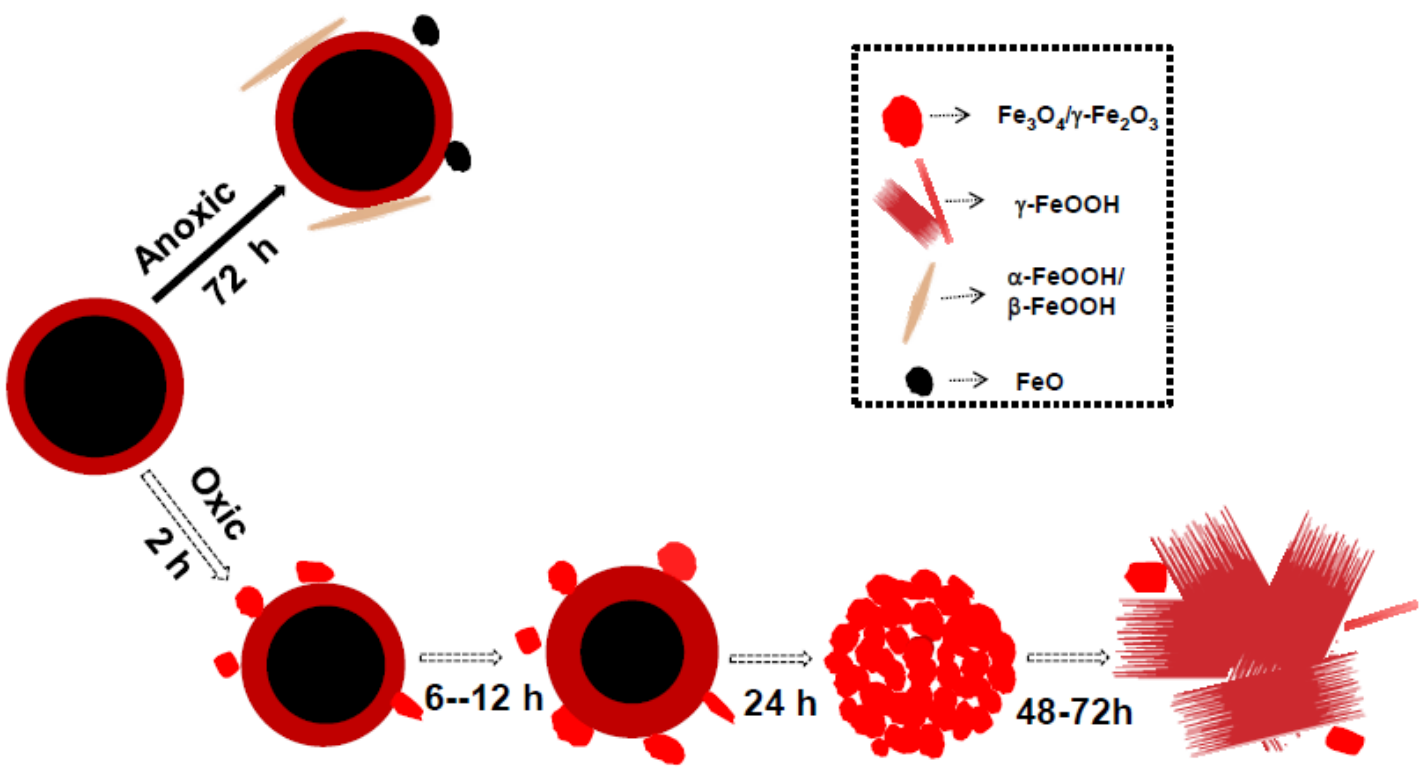

Fig.5. A conceptual model on $\mathrm{nZVI}$ evolution in water

\section{Conclusions}

Evolution of $\mathrm{nZVI}$ in water is studied by TEM, XRD, and Raman spectroscopy. Reactions at the $\mathrm{nZVI} /$ water interface influence the core-shell structure and the corrosion products. Images acquired by TEM provide detailed morphological and structural changes with the progress of time. Under anoxic conditions, the core-shell structure of $\mathrm{nZVI}$ is well maintained after $72 \mathrm{~h}$. Under oxic conditions, the core-shell structure quickly evolves. The particles may maintain the spherical shape at the initial corrosion stage, and eventually evolve into flaky and/or acicular-shaped structures. XRD and Raman spectra provide evidence that the components of corrosive nZVI vary with the aging time. The corrosion products of $\mathrm{nZVI}$ in anoxic water for $72 \mathrm{~h}$ are a complex mixture of $\mathrm{FeO}, \alpha-\mathrm{FeOOH}$ or/and $\beta-\mathrm{FeOOH}$. Under oxic conditions, $\gamma-\mathrm{FeOOH}$ is the primary final product. The patterns of SAED prove the single crystal of the product for $72 \mathrm{~h}$ oxidizing in water. Information on the componential, morphological, and structural evolution of $\mathrm{nZVI}$ under different conditions 
generates a detailed physical model of nZVI under different environments.

\section{Acknowledgements}

Research described in this work has been partially supported by the National Science Foundation of China (NSFC Grants 21277102, 21003151), the Science and Technology Commission of Shanghai (Grant 11JC1412600), and the Collaborative Innovation Center for Regional Environmental Quality.

\section{References}

1. W.L. Yan, H.-L. Lien, B.E. Koel, W.-X. Zhang, Iron nanoparticles for environmental clean-up: recent developments and future outlook, Environ. Sci.: Processes Impacts, 15 (2013) 63-77.

2. M. Khin, A.S. Nair, V.J. Babu, R. Murugan, S. Ramakrishna, A review on nanomaterials for environmental remediation, Energy \& Environ. Sci., 5 (2012) 8075-8109.

3. L. Ling, W.-X. Zhang, Enrichment and Encapsulation of Uranium with Iron Nanoparticle, J. Am. Chem. Soc., 137 (2015) 2788-2791.

4. W.-X. Zhang, Nanoscale iron particles for environmental remediation: an overview, J. Nanopart. Res., 5 (2003) 323-332.

5. A.R. Liu, W.-X. Zhang, Fine structural features of nanoscale zero-valent iron characterized by spherical aberration corrected scanning transmission electron microscopy (Cs-STEM), Analyst, 139 (2014) 4512-4518.

6. X.Q. Li , W.-X. Zhang, Iron nanoparticles: the core-shell structure and unique properties for Ni (II) sequestration, Langmuir, 22 (2006) 4638-4642.

7. B.C. Reinsch, B. Forsberg, R.L. Penn, C.S. Kim, G.V. Lowry, Chemical transformations during aging of zerovalent iron nanoparticles in the 
presence of common groundwater dissolved constituents Environ. Sci. Technol., 44 (2010) 3455-3461.

8. N. Kumar, M. Auffan, J. Gattacceca, J. Rose, L. Olivi, D. Borschneck, P. Kvapil, M. Jublot, D. Kaifas, L. Malleret, P. Doumenq, J.-Y. Bottero, Molecular Insights of Oxidation Process of Iron Nanoparticles: Spectroscopic, Magnetic, and Microscopic Evidence, Environ. Sci. Technol., 48 (2014) 13888-13894.

9. V. Sarathy, P.G. Tratnyek, J.T. Nurmi, D.R. Baer, J.E. Amonette, C.L. Chun, R.L. Penn, E.J. Reardon, Aging of iron nanoparticles in aqueous solution: effects on structure and reactivity, J. Phys. Chem. C, 112 (2008) 2286-2293.

10. L.F. Greenlee, J.D. Torrey, R.L. Amaro, J.M. Shaw, Kinetics of zero valent iron nanoparticle oxidation in oxygenated water, Environ. Sci. Technol., 46 (2012) 12913-12920.

11. J. Klausen, P.J. Vikesland, T. Kohn, D.R. Burris, W.P. Ball, A.L. Roberts, Longevity of granular iron in groundwater treatment processes: solution composition effects on reduction of organohalides and nitroaromatic compounds, Environ. Sci. Technol., 37 (2003) 1208-1218.

12. T. Kohn, K.J.T. Livi, A.L. Roberts, P.J. Vikesland, Longevity of granular iron in groundwater treatment processes: corrosion product development, Environ. Sci. Technol., 39 (2005) 2867-2879.

13. Q.L. Wang, S. Snyder, J. Kim, H. Choi, Aqueous ethanol modified nanoscale zerovalent iron in bromate reduction: synthesis, characterization, and reactivity, Environ. Sci. Technol., 43 (2009) 3292-3299. 
14. K.H. Sohn, S.W. Kang, S.Y. Ahn, M.W. Woo, S.K. Yang, Fe(0) nanopartcles for nitrate reduction: Stability, reactivity, and transformation, Environ. Sci. Technol., 40 (2006) 5514-5519.

15. H.-S. Kim, J.-Y. Ahn, K.-Y. Hwang, I.-K. Kim, I. Hwang, Atmospherically stable nanoscale zero-valent iron particles formed under controlled air contact: characteristics and reactivity Environ. Sci. Technol., 44 (2010) 1760-1766.

16. Y. Xie, Z. Fang, X. Qiu, E.P. Tsang, B. Liang, Comparisons of the reactivity, reusability and stability of four different zero-valent iron-based nanoparticles, Chemosphere, 108 (2014) 433-436.

17. I. Zhou, T.L. Thanh, J. Gong, J.H. Kim, E.J. Kim, Y.S. Chang, Carboxymethyl cellulose coating decreases toxicity and oxidizing capacity of nanoscale zerovalent iron, Chemosphere, 104 (2014) 155-161.

18. H.-S. Kim, J.-Y. Ahn, K.-Y. Hwang, I.-K. Kim, I. Hwang, Aging characteristics and reactivity of two types of nanoscale zero-valent iron particles $\left(\mathrm{Fe}^{\mathrm{BH}}\right.$ and $\mathrm{Fe}^{\mathrm{H} 2}$ ) in nitrate reduction, Chem. Eng. J., 197 (2012) $16-23$

19. Q.L. Wang, S. Lee, H. Choi, Aging Study on the Structure of $\mathrm{Fe}^{0}$-Nanoparticles: Stabilization, Characterization, and Reactivity, J. Phys. Chem. C, 114 (2010) 2027-2033.

20. B.C. Reinsch, B. Forsberg, R.L. Penn, C.S. Kim, G.V. Lowry, Chemical Transformations during Aging of Zerovalent Iron Nanoparticles in the Presence of Common Groundwater Dissolved Constituents, Environ. Sci. Technol., 44 (2010) 3455-3461. 
21. A.R. Liu, J. Liu, W.-X. Zhang, Transformation and composition evolution of nanoscale zero valent iron ( $\mathrm{nZVI}$ ) synthesized by borohydride reduction in static water, Chemosphere, 119 (2015) 1068-1074.

22. L.F. Greenlee, J.D. Torrey, R.L. Amaro, J.M. Shaw, Kinetics of Zero Valent Iron Nanoparticle Oxidation in Oxygenated Water, Environ. Sci. Technol., 46 (2012)12913-12920.

23. S.L. Li, W. Wang, Y.Y. Liu, W.-X. Zhang, Nanoscale zero-valent iron (nZVI) for the treatment of concentrated $\mathrm{Cu}(\mathrm{II})$ wastewater: a field demonstration, Environ. Sci.: Processes Impacts, 16 (2014) 524-533.

24. S.L. Li, W. Wang, Y.Y. Liu, W.L. Yan, Zero-valent iron nanoparticles (nZVI) for the treatment of smelting wastewater: A pilot-scale demonstration, Chem. Eng. J. 254 (2014) 115-123.

25. Y.P. Sun, X.Q. Li, J.S. Cao, W.-X. Zhang, H.P. Wang, Characterization of zero-valent iron nanoparticles, Adv. Colloid Interfac., 120 (2006) 47-56.

26. D.D. Boland, R.N. Collins, C.J. Miller, C.J. Glover, T.D. Waite, Effect of solution and solid-phase conditions on the $\mathrm{Fe}(\mathrm{II})$-accelerated transformation of ferrihydrite to lepidocrocite and goethite, Environ. Sci. Technol., 48 (2014) 5477-5485.

27. A.R. Liu, J. Liu, B.C. Pan, W.-X. Zhang, Formation of Lepidococite $(\mathrm{y}-\mathrm{FeOOH})$ from Oxidation of Nanoscale Zero-Valent Iron $(\mathrm{nZVI})$ in the Oxygenated Water, RSC Adv., 4 (2014) 57377-57382.

28. S.R. Kanel, B. Manning, L. Charlet, H. Choi, Removal of arsenic(III) from groundwater by nanoscale zero-valent iron, Environ. Sci. Technol., 39 (2005) 1291-1298.

29. B.A. Manning, M.L. Hunt, C. Amrhein, J.A. Yarmoff, Arsenic(III) and 
arsenic(V) reactions with zerovalent iron corrosion products, Environ. Sci. Technol., 36 (2002) 5455-5461.

30. D.Q. Yang, E. Sacher, Uniformly Dispersed Pt-Ni Nanoparticles on Nitrogen-Doped Carbon Nanotubes for Hydrogen Sensing, J. Phys. Chem. C, 114 (2009) 6418-6425.

31. Y.H. Huang, T.C. Zhang, Effects of dissolved oxygen on formation of corrosion products and concomitant oxygen and nitrate reduction in zero-valent iron system, Water Res., 39 (2005) 1751-1760.

32. M.K. Nieuwoud, J.D. Comins, I. Cukrowsk, The growth of the passive film on iron in $0.05 \mathrm{M} \mathrm{NaOH}$ studied in situ by Raman micro-spectroscopy and electrochemical polarisation. Part I: near-resonance enhancement of the Raman spectra of iron oxide and oxyhydroxide compounds, J. Raman Spectrosc., 42 (2011) 1335-1339.

33. H. Monika, Raman spectroscopy of iron oxides and (oxy) hydroxides at low laser power and possible applications in environmental magnetic studies, Geophys. J. Int., 77 (2009) 941-948.

34. Y.S. Li, J.S. Church, A.L. Woodhead, Infrared and Raman spectroscopic studies on iron oxide magnetic nano-particles and their surface modifications, J. Magn. Magn. Mater., 324 (2012) 1543-1550.

35. Z. Shi, J.T. Nurmi, P.G. Tratnyek, Effects of nano zero-valent iron on oxidation-reduction potential, Environ. Sci. Technol., 45 (2011) 1586-1592. 


\section{Graphical Abstract}

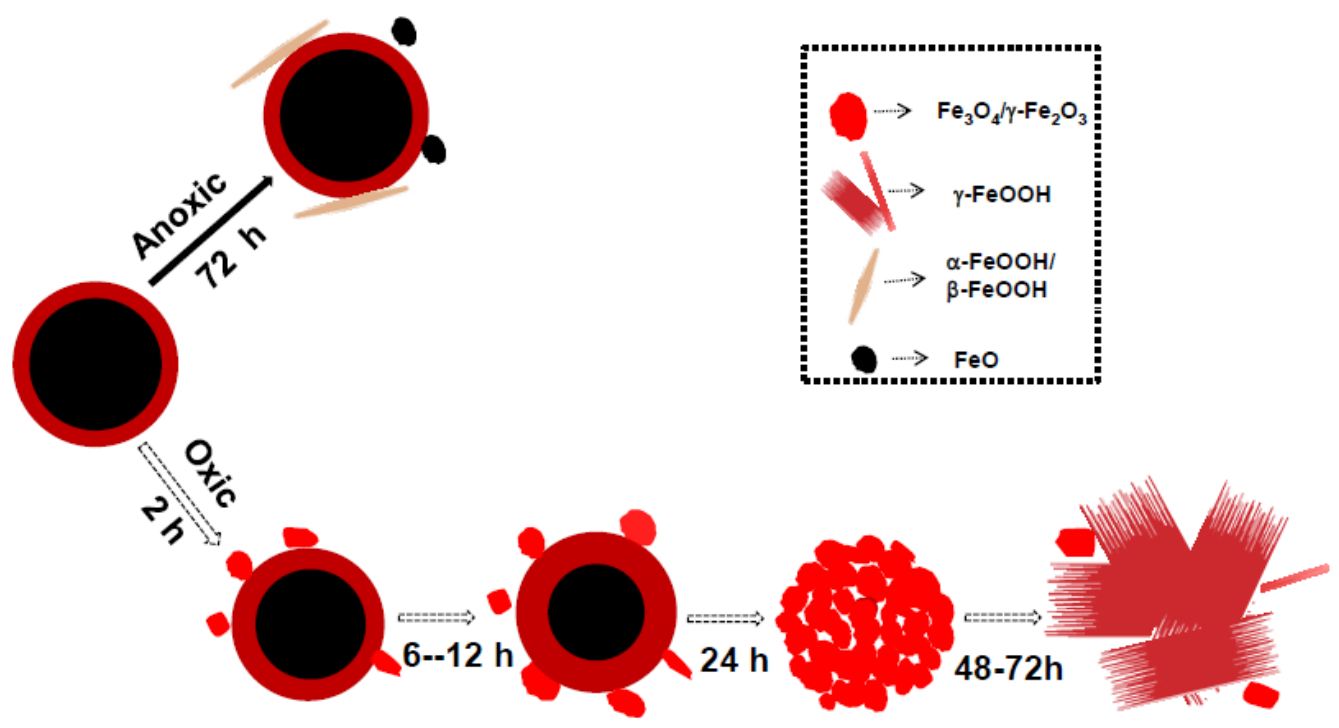

